mediastudies.press • Social Media \& the Self: An Open Reader

\title{
The Management of Information About Oneself
}

\section{Erving Goffman}

Published on: Jan 01, 1953

DOI: $10.32376 / 3 f 8575 c b . e 188 d 2 d 9$

License: Creative Commons Public Domain Dedication (CC-0 4.0). 
There are some additional qualifications necessary, in the practical part of business, which may deserve some consideration in your leisure moments-such as, an absolute command of your temper, so as not to be provoked to passion upon any account; patience, to hear frivolous, impertinent, and unreasonable applications; with address enough to refuse, without offending; or, by your manner of granting, to double the obligation;-dexterity enough to conceal a truth, without telling a lie; sagacity enough to read other people's countenances; and serenity enough not to let them discover anything by yours-a seeming frankness, with a real reserve. These are the rudiments of a politician; the world must be your grammar. $\underline{1}$

IN SOCIAL LIFE, an actor commonly finds that very basic ends, of both an ultimate and intermediate kind, are furthered by gathering information about those with whom he interacts, especially information about the conceptions that these persons have of themselves and of him. With information about others, the actor can predict in general their likely behavior, and prepare for it. With information of this kind, he can determine how best to shape his own behavior in order to call forth a desired action from others. (The exploitation of the indicated likely response of others to his own behavior is required, of course, whether the actor wishes to please or to displease the others.) With information of this kind, the actor can learn what is expected of him and "where he stands" with respect to the others, helping thus to determine for himself who and what he is. We find, then, a whole complex of ends, any one or more of which may motivate the actor to the same kind of activity, i.e., an effort to find out as much as possible about the persons with whom he interacts.

The expressive function of behavior has to do with the tendency of events associated with the actor to carry information about the actor. This process has, intrinsically, nothing whatsoever to do with communication of a linguistic and intentioned kind. Expressive information is there whether or not anyone realizes this to be the case. Specialists in "human relations" recognize that they must exploit all sources of information, linguistic and expressive, that are available to them, since it is appreciated that the subject's linguistic version of the situation may be a highly biassed [sic] one. Thus, we are given advice of the following kind:

When you talk with the patient, you should listen, first, for what he wants to tell you, secondly, for what does not want to tell, thirdly, for what he cannot tell. $\underline{2}$ 
It is interesting to note that certain patients also make use of expressive cues as a source of information. Fromm-Reichmann, for instance, makes the fellowing suggestion concerning schizophrenic patients:

The schizophrenic's ability to eavesdrop, as it were, on the doctor creates another special personal problem for some psychiatrists. The schizophrenic, since his childhood days, has been suspiciously aware of the fact that words are used not only to convey but also to veil actual communications. Consequently, he has learned to gather information about people in general, therefore also about the psychiatrist, from his inadvertant [sic] communications through changes in gesture, attitude and posture, inflections of voice or expressive movements. $\underline{3}$

But, of course, this kind of detective work goes on constantly in non-professional situations; in every interaction, each participant is both patient and doctor. In Ichheiser's terminology, sources of expression of one person come to be sources of impression of him for other persons. $\underline{4}$ Of all the actual sources of expression that exist concerning any actor, those which occur while the actor is engaged in linguistic communication are perhaps the most important. These sources are important because if a recipient is in a position to receive a linguistic communication in a face-to-face context, he is also thereby in an excellent position to observe the sender closely. It should be noted that a linguistic message involves a certain amount of active communication, transmission, or "sending" on the part of the sender and a certain amount of passive receptivity on the part of the recipient. In the case of expressive information, on the other hand, the impression or message is not so much sent as it is taken, the message is not so much communicated as it is conveyed; here the recipient must in many respects play a more active role than the sender.

It has been suggested that a whole complex of ends is served for the actor when he obtains information about the other. Consequently, recipients of a linguistic message tend to scrutinize the expressive behavior of the sender of the message. In many cases, of course, the sender has as good a motive for trying to prevent the flow of information about himself as his observers have for seeking this information. The only end that cannot be served for the sender by the exercise of information control is that of free and spontaneous self-expression, and this is not so much an end of action as it is a characteristic of the behavioral impulse. The sender typically exerts tactical control, therefore, over his linguistic communication. He also tends to exert control over the expressive component of his behavior in an attempt to influence the response that recipients are like to have to it. 
In general, a person who wishes to exert control over the information about self which others are able to acquire about him may communicate misinformation, inadequate information, or unserious information. $\underline{5}$

Misinformation may be communicated by linguistic signs. This may be called deceit. In immediate communication, deceit does not occur frequently except under special circumstances, as in the "white lie." Persons who practise more serious deceit, e.g., the "bare-faced lie," and who are detected, place themselves in an almost indefensible position. Misinformation may be conveyed by expressive signs. This may be called feigning. Feigning occurs quite regularly, partly because the signs employed may refer to mental or emotional states which no one can completely prove that the sender does or does not possess. $\underline{6}$

Inadequate information may be communicated by linguistic signs. A person who acts in this way is said to lack candor and frankness, to be close-lipped. When this reticence pertains to specific issues, as it may, for example, in the criminal world, we speak of clamming up. When a person provides inadequate expressive information, we sometimes think of him as being "cold" or disdainful. Some games of chance are specifically designed to give play to the faculty for expressive constraint, and the term poker-face, starting as a word applying to a game, has become widely used in ordinary social contexts. $\underline{7}$

The transmission of misinformation and inadequate information appears to be a very general practice, although we have little systematic knowledge as to where in a given social structure it is practised the most and with what degree of success in carrying conviction. $\underline{8}$ Recently Margaret Mead has given us an extreme example:

With this requirement, that all behavior be controlled and directed toward Party goals, goes the requirement that the Party member treat himself as a tool to carry out the wishes of the Party, but that he be at all times a conscious tool, voluntarily submitting himself to the discipline of the Party. And the discipline must be minute and detailed, over himself and over his every movement. So an informant reports an encounter with a Soviet professor in Berlin, who told her that he smoked a pipe "because while smoking a pipe the fact does not reveal so much." Then he added: "See, this we learned during the Soviet period. Before the revolution we used to say: 'The eyes are the mirror of the soul.' The eyes can lie-and how. You can express with your eyes a devoted attention which in reality you are not feeling. You can express serenity or surprise. I often watch my face in the mirror before 
going to meetings and demonstrations and ... I was suddenly aware that even with a memory of a disappointment my lips became closed. That is why by smoking a heavy pipe you are sure of yourself. Through the heaviness of the pipe the lips become deformed and cannot react spontaneously. $\underline{9}$

In Dixon, the practice of conveying misinformation or inadequate information seems well developed. Frustrations that occur in the pursuit of everyday tasks are rarely a cause of outbursts of anger and are usually taken with apparent calmness and coolness, as a matter of course. When a housewife accidentally burns her finger on a hot pot or puts too much salt in a soup, when two men have to try time and time again to move a cow from one field to another, when a fish net gets torn on the rocks of the floor of the inlet and must be drawn up for a day's work of mending-in these and many other daily frustrations very little emotional expression is allowed to escape. Occurrences which call forth frustration and deprivation are said, merely, to be “awkward." $\underline{10}$ So, too, when a young man leaves Dixon for a year or two to work as a seaman, or when he returns after having been away for this reason, his womenfolk will bid farewell to him at the pier, or greet him there, without kissing him and with very little show of emotion, yet family ties seem to run extremely deep. And, finally, persons who are not Berganders are treated with politeness and distance, and any opinions which they express are often answered with very mild agreement; so smooth is this treatment that outsiders frequently never realize how little they have learned. $\underline{11}$

It has been suggested that a sender may convey misinformation, both linguistically and expressively, and that he may convey insufficient information, both linguistically and expressively. In the interests of completeness, a final possibility must be considered. The sender may convey unserious information. A complex relation between context, expressive cues, and linguistic content of the message establishes the assumption that recipients are not to give credence to the sender's message and that the sender is not to be made responsible for what he has said. Recipients are officially meant to understand that what is conveyed to them, especially the linguistic components of the message they receive, is exactly what the sender does not believe; what the sender does believe is left an open question. The right to be unserious is a right to play at communication $\frac{12}{2}$; it represents an important communication license and it is employed in many different ways for many different purposes. It should be understood that almost any particular piece of information, linguistic or expressive, can be communicated seriously or unseriously, depending on the context and the spirit of the communication. A decision on the part of a sender to treat a matter unseriously is, of 
course, a quite serious thing in most cases; this decision can be employed by recipients as a source of impression about the sender. It would seem that efforts on the part of a sender to define his message unseriously are usually acknowledged and accredited by recipients. If a sender's attempt to maintain an unserious definition of the situation is unacceptable to recipients, they cannot hold him responsible for the linguistic component of his message but they can hold him responsible for a breach of good taste and for improper joke making. In Dixon, the art of unseriousness seemed to be highly developed. Three special ways of talking are set aside for this purpose: simulated babytalk; simulated Public School accents; and formulation of a message in no-longercurrent forms of Bergand dialect. "Straight-faced" teasing and mock affront are also employed extensively. $\underline{13}$

It has been suggested that a sender may attempt to exert control over the other's response to him by inhibiting his spontaneous response to the situation and conveying, instead, misinformation, inadequate information, and unserious information. Thus an actual message may contain information which purposely obscures from view the real feelings and thoughts of the sender. Recipients may, of course, come to realize that the sender is interested in controlling the impression given, and they may come to anticipate a distortive or tactical element in the messages they receive. In order to get through the screen of distortions, evasions, omissions, etc., to the "real" feelings and conceptions of the sender, recipients may have to examine each message to find out what can be accepted at "face value" and what has to be analyzed and translated so as to reveal the real information that is hidden by it. $\underline{14}$ In the terminology of cryptography, the recipient may find that part of the message is "clear," that is, it can be taken at its face value, and that another part of the message is "coded," that is, it is a distortion of some kind and must be decoded before providing truthful information.

We usually feel that clear information is conveyed by expressive emotional behavior during times of crisis and that coded information comes to us through linguistic messages when a person is "on his guard." This may be usually the case but it is not necessarily so. Occasionally a sender communicates linguistically his real feelings and thoughts. The significant point here is that moral norms seem to develop regulating the amount and the place for clarity and coding in messages in a particular situation. Further, the sender and the recipient each develops his own version as to what part of the message is coded and what part is clear; they each develop a version of the discrepancy between clear and coded parts of the message. In conversational interaction, then, we find an interesting set of discrepancies: a socially permitted discrepancy defined as appropriate for situations like the given one; the "objective" 
discrepancy which in fact exists between the coded and the clear information in the given situation; the opinion of the sender and of the recipient as to what is in fact the objective discrepancy between the clear and coded parts of the message. Discrepancies between these several discrepancies provide one way of describing certain kinds of interpersonal communication problems.

When persons are engaged in conversational interaction, those who are recipients seem to participate in two streams of signs, linguistic signs and expressive signs. At the same time, those who send messages of a linguistic kind seem to participate chiefly in the purely linguistic aspect of their own behavior. Thus, if the term communication be employed broadly to cover the process by which a recipient acquires both streams of signs (receiving one, taking the other), then we see that communication is usually asymmetrical; the sender is involved in one stream of signs, the recipients in two. As Simmel suggests:

... all of human intercourse rests on the fact that everybody knows somewhat more about the other than the other voluntarily reveals to him ... $\frac{15}{1}$

When the expressive stream of signs is cut off, as it can be in mediated communication, then real problems of understanding arise. This is nicely described by Whyte in his discussion of the difficulties arising in restaurants from the use of mechanical devices for transmitting orders from waitresses to cooks:

To build better teamwork in the supply system, management needs to think in terms of communication and status. We have seen clearly that mechanical devices are not an adequate substitute for face-to-face communication. Nor is this simply because the particular words that come over the public address system, teleautograph, or phone are sometimes misunderstood. We make our judgment as to other people not alone through the bare words we utter but through the way we express ourselves, through our gestures and facial expressions, and through our past experience with this relationship, which tells us how to interpret the other man's behavior. Nearly all of this background for adjustment, understanding, and cooperation is lost when people are separated so that interaction is filtered through mechanical devices. $\underline{16}$

In his essay entitled, "Behind Our Masks," Park makes much the same point: It is curious and interesting that this character that we call human should be so intimately connected with expressiveness. Human interest, as we ordinarily use 
that phrase, attaches to anything that is "expressive"; that is, to anything that suggests, symbolizes or reveals sentiments and passions in others of which we are immediately conscious in ourselves. The faces we know have no secrets for us. For that reason, if for no other, we feel secure and at home with them as we do not among less familiar faces....

One of the first and most important discoveries the one who meets an alien people for the first time is likely to make, is that, different as they seem, most strange people, when you come to know them, turn out to be human, like ourselves. It always requires an effort of imagination to realize this. It is because their faces are for us not expressive; and we, in turn, do not respond to sentiments whose expression we are not able to read. $\underline{17}$

We have suggested that a sender often has reason to attempt to control the response that his messages evoke and hence has reason to attempt to control "with malice aforethought" the expressive component of his behavior. A limited amount of this instrumental use of an essentially non-instrumental aspect of behavior is socially permissible, especially in certain situations, as in greetings and farewells, where a certain amount of ungenuine expressive behavior is permissible, although strong sanctions are exerted against those who are felt to have affected expressive behavior at inappropriate times. Further, a certain additional amount of calculated employment of one's expressive behavior is no doubt accomplished without detection. In general, however, it seems that a sender cannot tamper with what ought to be the expressive component of his communication, or even became aware of the probable effect on recipients of this component, without this concern itself being communicated in an expressive way. The asymmetrical character of the communication process thus remains, but it occurs at a somewhat different level. The recipient checks up on the linguistic component by means of what ought to be the genuinely expressive halo of signs associated with it, and then checks up on this presumed expressive behavior by examining the fugitive stylistic features of it that are almost impossible to feign.

It has been suggested that a sender is often motivated to restrict the information which he advertantly [sic] or inadvertantly [sic] makes available about himself, and that a recipient is motivated to acquire as much information about the sender as possible. We often find, then, that conversational interaction involves a constant game of concealment and search, and that in this game a given player will usually be better at the task of discovering things about the other than at the task of concealing things from him. $\underline{18}$ For example, a crofter's wife has admitted to me (and I have also 
observed) that in order to find out whether a guest "really" likes the food he is being served, she does not listen to his words of praise, which courtesy demands of him, but observes the rapidity with which he raises the food to his mouth and the zest with which he chews it. Such cues to the attitude of an actor are extremely difficult to distort. Extreme applications of this game of concealment and search, operating at an institutionalized level, are found in the application of modern projective testing and the use of laboratory police methods.

For a close analysis of conversational interaction, it is useful to give consideration to the level of care that a recipient feels he must exert in regard to the reception of a particular message. It is also useful to know to what lengths the recipient feels he must go in order to find clear information in the message or in order to decipher the coded information. At the lowest level of sophistication in the game of concealment and search we find this: the sender transmits a message which he implicitly assumes the recipient will take at face value, as consisting wholly of clear information; at the same level the recipient assumes that the message contains clear and coded components and that the sender is unaware that this discrimination is being made. At the next level of sophistication, the sender takes into consideration the recipient's double assumption, namely that the message has both clear and coded components and that the sender is not aware that this discrimination is being made by the recipient. In poker and in other social contexts, this is called bluffing. At the same level of sophistication, the recipient maintains the usual asymmetry of the communication process by perceiving the bluff and guiding his response accordingly. At a third level, we have the practice whereby a sender bluffs that he is bluffing and a recipient bluffs that he is being taken in by a bluff. An infinite regress is imaginable, but three levels in this process seem to be all that we need to consider in most situations.

In Chapter IV, a clearcut analytical distinction was made between linguistic behavior, as an intentioned and instrumental activity, and expressive behavior, as an impulsive, non-rational aspect of behavior, having nothing to do with communication in the narrow sense of that term. However, in the present chapter it has been necessary to recombine these two modes of behavior in an intricate way. For one thing, recipients exploit the expressive behavior of a sender as a source of impression about him. Secondly, the sender may attempt to exploit the fact that this exploitation occurs and attempt to express himself in a way that is calculated to impress the recipient in a desired way. What on the surface is expressive behavior becomes, then, in a sense, instrumental behavior. 
Let us restate and amplify slightly the ways in which expressive behavior and linguistic behavior intermingle and complicate each other. First, we find that the recipient, unbeknownst to the sender, derives information about the sender by examining his expressive behavior. This expressive stream of signs does not involve the sender in an active communicative role; it adds to his active role as a linguistic communicator a passive role as an expressive object. If the sender then becomes aware that he has conveyed two streams of information, one linguistic and one expressive, his role as an expressive object becomes a little less passive. Further, the sender may realize beforehand that the expressive component of his behavior will be audited, and attempt, in a surreptitious way, to enact the kind of expressive behavior which is likely to call forth the kind of response that he wishes to evoke from his recipients. The sender may be successful in his bluff or detected at it; in either case, expressive behavior takes on an instrumental function and becomes an activity more closely akin to what we think of as communication. Finally, the sender may modify his expressive behavior "with malice aforethought," at the same time openly conveying that this calculated display of expressive behavior is intentional. This sometimes seems to be the case with certain conventionalized gestures of respect and approval and with "etiquette" in general. $\underline{19}$ Here a certain amount of feigning (and deceit) is felt to be socially permissible. In these cases, expressive behavior becomes an active form of communication. However, intentionally employed expressive behavior does differ from linguistic behavior in significant ways. Intentionally employed expressive behavior, however "conventionalized" it becomes, must take the form of behavior that could possibly be unselfconsciously or spontaneously expressive, and, as in the case of genuinely expressive behavior, the sender cannot be made officially responsible for having conveyed the information carried by it. Thus we are able to see that official signals, such as raising one's hand for attention, which form part of linguistic behavior, may be quite similar in appearance to intentionally employed expressive gestures, such as raising one's hat to a woman, and yet the first sign is part of an officially accredited aspect of communication-what might be called the formal aspect-while the second sign is part of an unofficial or informal aspect of communication.

We find, then, when we examine persons engaged in conversational interaction, that a very complex dialectic is in progress between the formal or linguistic component of communication and the informal or expressive component of communication and that the latter itself contains a host of messages which differ among themselves in the degree to which they approach what we usually think of as active communication. 
It has been suggested that both sender and recipient can be made explicitly responsible for a linguistic message, the sender for having transmitted it and the recipient for having received it. Playing in and around this major theme, there are many variations and melodies, which now embellish, now oppose, now develop, now reinforce, the dominant theme. These variations are conveyed by expressive behavior and provide for a somewhat irresponsible kind of communication; the sender cannot be explicitly and specifically held accountable for the content of these messages, and the recipient has the right to act as if he has not received them. The contrapuntal interweaving of responsible transmission with irresponsible transmission seems to make for flexibility. Persons can give lip service to a message that has been accepted or that is acceptable, while at the same time conveying by informal expressive means information that would disrupt the working acceptance if it were conveyed linguistically.

Perhaps the most obvious example of the flexibility provided by the interweaving of the two components of communication is to be found in what is called in everyday terms "innuendo." Innuendo occurs when the informal expressive component of communication carries information that is radically opposed to or different from the information carried by the linguistic component and when, at the same time, the sender conveys the fact that he expects the recipient to be impressed by this divergent expressive component. Sometimes innuendo is used by a sender to convey compliments which he is not in a position to deliver explicitly; usually, apparently, innuendo is employed as a means of conveying disagreements, criticisms, and depreciatory judgments which might put the working acceptance in jeopardy were they conveyed linguistically. Often innuendo is conveyed by statements made "unseriously." $\underline{20}$

\section{REPRINT}

"Chapter V: The Management of Information About Oneself" (Erving Goffman, Communication Conduct in an Island Community (PhD diss., University of Chicago, 1953): 71-89)

PUBLIC DOMAIN

\section{Footnotes}

1. Letters of Lord Chesterfield to His Son, Everyman's ed. (New York: Dutton, 1929), p. $41 . \triangleq$ 
2. L. J. Henderson, "Physician and Patient as a Social System," New England J. of Med., CCXII (819-823), 822.

3. Frieda Fromm-Reichmann, "Notes on the Development of Treatment of Schizophrenics by Psychoanalytical Psychotherapy,” Psychiatry, XI (263-273), 273. 4. Gustav Ichheiser provides a clear statement of the difference between expression and impression on pp. 6-7 of his monograph, "Misunderstandings in Human Relations," Supplement to The American Journal of Sociology, Sept. 1949 (Chicago: University Chicago Press, 1949).

5. Professional rules in service trades sometimes explicitly deal with the degree to which different kinds of mis-communications are officially permissible. See, for example, E. C. Hughes, "Study of a Secular Institution: the Chicago Real Estate Board," (Unpublished Ph. D. dissertation, Department of Sociology, University of Chicago, 1928), p. 85: "The line between misrepresentation and truth is hard to draw. The code deals with three types of questions regarding truth, (1) overstatement, (2) understatement of unfavorable facts, and (3) silence regarding significant facts which have not been asked for." $\doteq$

6. In the case of feigning or dissimulation, the sender appreciates that his expressions are "false" and misinformative; they are employed, in fact, precisely in order to throw the observer "off the scent." A more important communication behavior is that of affectation, where a sender's expressive gestures are seen to be a product of calculation and design, while at the same time the impression is given that the sender is at least partly taken in by his own act and partly convinced that he is in fact the sort or person that his affectations attempt to establish. Affectation or posing is a crucial communication possibility and will be considered in chap. xix. $\leftrightarrows$ 7. It is an interesting fact that in some cultures the practice of making no expressive response in some situations is institutionalized in the form of a slight smile, this sign becoming a way of openly communicating that one is not expressively communicating. $\leftrightarrows$

8. For a consideration of a social situation in which there arises the use of statements that are technically true but by implication false or insufficient, see Fritz J. Roethlisberger, "The Foreman: Master and Victim of Doubletalk," Human Factors in Management, ed. S. D. Hoslett (New York: Harper, 1946), pp. 51-73, especially pp. 58-59. $ヒ$ 
9. Margaret Mead, Soviet Attitudes toward Authority (New York: McGraw-Hill, 1951), pp. 65-66.

10. British gentry have a somewhat similar affective stress, labelling extremely deprivational events "a bore." $ヒ$

11. It is sometimes claimed that "expressive" withdrawal on the part of crofters in Bergand is related to their historical status in relation to the Lairds. Until the crofting act of 1895, a landlord had the right to increase rent without warning and in any amount. Widely appreciated tradition has it that any show of prosperity on the part of a crofter would have immediately led to an increase in his rent. Hence, it is felt that crofters had no motive for "bettering" themselves, and that there was a natural reason to conceal, physically and verbally, the slightest gain in wealth and one's plans and feelings in general. $\leftrightarrows$

12. The best treatment of unseriousness that I know of may be found in Kurt Riezler, "Play and Seriousness," J. of Philosophy, XXXVIII, 505-517. A sender may (for many different motives) play at play, or, in this case, treat unseriousness unseriously, by attempting to keep the note of levity from his voice as long as possible and by attempting to mimic completely the serious expressive tone normally associated with the linguistic message being sent. This communication game will be considered later.

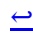

13. Another favorite mode of unseriousness, but of a somewhat more formal kind, is play-acting - a very popular form of amusement on the island. During the year, skits and plays are put on at least two socials in each of the communities. Certain kinds of skits, such as ones involving ministers, are felt to be in bad taste by some of the more "fundamentalist" of the crofters. In Capital City, where an annual drama festival is held, plays that are too realistically dramatic, such as Synge's Riders to the Sea, are also felt by some to be improper vehicles for the stage. $\bullet$

14. One decoding method is to treat the sender's choice from the many possible modes or distortion as an expression or the sender. $€$ 15. Simmel, [The Sociology of Georg Simmel (Glencoe, IL: The Free Press, 1950], p. 323.

16. William F. Whyte, Human Relations in the Restaurant Industry (New York: McGraw-Hill; 1948), p. 60. 
17. Robert Ezra Park, [Race and Culture (Glencoe, IL: The Free Press, 1950)], pp. 252-253.

18. Perhaps here it should also be noted that in circles conversant with Freudian doctrine, "slips" are taken, jokingly or otherwise, as a revelation of "real" feelings; since slips are apparently in no way subject to conscious control, they may convey embarrassing information, or what is taken to be embarrassing information. The doctrine that slips are "significant" adds new hazards to the concealer, gives new power to the searcher. $\uplus$

19. It is extremely difficult to make judgments concerning the degree of unselfconscious spontaneity involved in the performance of a given piece of social ritual or ceremony. It seems that one can say, however, that forms of etiquette which seem arbitrary, empty gestures at the time they are consciously learned may easily come, with the passage of years, to be unthinking and genuinely expressive aspects of one's behavior. $\subseteq$

20. In general there is a sense in which the two forms of communication license, unseriousness and innuendo, are the reverse of each other, even though they may both add flexibility and adaptability to conversational interaction. In the case of unseriousness, the recipient is obliged to overlook the linguistic component of the message, which, if taken seriously, would disrupt the working acceptance. In the case of innuendo, the recipient is obliged to overlook the expressive component, which, if conveyed linguistically, would disrupt the working acceptance. Innuendo provides an explicit agreement while conveying the fact that one really doesn't exist; unseriousness provides an explicit disagreement while conveying the fact that one really exists. When unseriousness is pressed into the service of innuendo we obtain a serious use of unseriousness; the great frequency with which this communication arrangement is employed should not lead us to underestimate the complexity and subtlety of the arrangement. $ヒ$ 